\title{
O OBJETIVO FUNDAMENTAL CONSTITUCIONAL DE ERRADICAÇÃO DA POBREZA
}

\author{
THE FUNDAMENTAL CONSTITUTIONAL PURPOSE OF ERADICATING POVERTY
}

\section{Ricardo Hasson Sayeg}

Doutor e Mestre em Direito Comercial pela Pontifícia Universidade Católica de São Paulo (PUC-SP) Professor Livre Docente de Direitos Humanos - Mestrado e Doutorado e Coordenador na Graduação da Disciplina de Direito Econômico do Departamento de Ciências Tributárias, Econômicas e Comerciais da Faculdade de Direito e Líder do Grupo de Pesquisa Capitalismo Humanista certificado pelo CNPq da Pontifícia Universidade Católica de São Paulo (PUC-SP) Membro do Conselho Superior da CAPES do Ministério da Educação e Cultura.

E-mail: ricardo@hslaw.com.br

\section{Wagner Balera}

Doutor e Mestre em Direito Tributário, Doutor em Direito das Relações Sociais e Livre-Docente em Direito Previdenciário pela Pontifícia Universidade Católica de São Paulo (PUC-SP) Professor Titular de Direitos Humanos, Coordenador do Núcleo de Direitos Humanos e Líder do Grupo de Pesquisa sobre Direito e Direitos dos Refugiados da Pontifícia Universidade Católica de São Paulo (PUC-SP) Membro da Academia Paulista de Direito, da Academia Paulista de Letras Jurídicas, da Academia Nacional de Seguros e Previdência e da Academia Brasileira de Direito Tributário

E-mail: balera@terra.com.br

Recebido em: 17/12/2018

Aprovado em: 06/03/2019

\begin{abstract}
RESUMO: O presente estudo tem como tema principal a erradicação da pobreza como objetivo fundamental constitucional. Busca-se, por meio do método hipotético-dedutivo e comparativo, dialogar com a Resolução "Transformando Nosso Mundo: a Agenda 2030 para o Desenvolvimento Sustentável”, que propõe 17 Objetivos do Desenvolvimento Sustentável e 169 Metas correspondentes, e a Constituição de 1988 do Brasil. Para isso no primeiro item será trabalhado a erradicação da pobreza de forma geral e no segundo a erradicação da pobreza como objetivo fundamental constitucional do Brasil. Com isso pretende-se justamente responder se há diálogo entre Agenda 30 e a Constituição Federal em relação a erradicação da pobreza e se essa constituise como um elemento fundamental constitucional.
\end{abstract}

Palavras-chave: Erradicação da Pobreza; Agenda 30; Objetivos do Desenvolvimento Sustentável; Constituição brasileira; Direitos Fundamentais.

ABSTRACT: The main theme of this study is the eradication of poverty as a fundamental
constitutional objective. Through the hypothetical-deductive and comparative method, we seek to
dialogue with the Resolution "Transforming Our World: The 2030 Agenda for Sustainable
Development", which proposes 17 Sustainable Development Objectives and 169 corresponding
goals, and the 1988 Brazilian Constitution. For this, the first topic will address the subject
eradication of poverty in general and, the second topic, the eradication of poverty as a fundamental 
constitutional objective of Brazil. With this, it is precisely intended to answer if there is a dialogue between Agenda 30 and the Brazilian Constitution regarding the eradication of poverty and whether this constitutes a fundamental constitutional element.

Keywords: Poverty Eradication; Agenda 30; Objectives of Sustainable Development; Brazilian Constitution; Fundamental Rights.

SUMÁRIO: Introdução; 1 A Erradicação da Pobreza e a Agenda 2030 para o Desenvolvimento Sustentável; 2 A Erradicação da Pobreza como objetivo fundamental constitucional; Conclusão; Referências.

\section{INTRODUÇÃO}

As tentativas de abolição da propriedade privada pelo socialismo naufragaram, tendo o leste europeu socialista caído, mercê de sua própria ineficiência em face do oeste da Europa, no que tange à comparação dos indicadores sociais. Na Europa, foi a qualidade de vida das pessoas do oeste, o principal desconstrutor dos regimes socialistas do leste, fazendo, de uma vez por todas, ruir a crença no comunismo e, consequentemente, prevalecer o capitalismo global e a economia de mercado. Na América do Sul, o regime político econômico da Venezuela reafirma o desastre que o socialismo representa para o bem estar da população.

Neste contexto econômico, apesar da crise do Capitalismo global, deflagrada em 2008, o neoliberalismo ainda prevalece na economia mundial, estabelecendo para o Planeta a globalização econômica capitalista. Em sua formatação original, tal processo se estrutura juridicamente em uma concepção antijudicialista, antropocêntrica, individualista e hedonista, apoiada no pensamento clássico de Adam Smith e David Ricardo.

O regime capitalista e a economia de mercado são realmente necessários, eficientes e recomendáveis, mas não há como desconsiderar sua principal implicação negativa, consubstanciada na exclusão do circuito econômico, político, social e cultural de parcela substancial da Humanidade, chegando ao ponto crítico de colocá-la à mercê do flagelo da pobreza, que significa a ausência de capacidade de integração econômica da pessoa humana.

A pobreza corresponde à privação das condições dignas de vida pela pessoa humana, naquilo que não seja fornecido pelo Estado e por benemerência. Não existe autodeterminação, muito menos liberdade, em uma situação de pobreza, uma vez que a pessoa humana fica inexoravelmente subjugada. Não é à toa que a dimensão social dos direitos humanos também é conhecida como a das liberdades positivas.

A luta contra a pobreza é, antes de tudo, a luta pela liberdade e autodeterminação dos Homens e de todos os Homens, o que é um dos sustentáculos do próprio neoliberalismo e economia de mercado.

Nesse trabalho, busca-se, portanto, por meio do método hipotético-dedutivo e comparativo, dialogar com a Resolução "Transformando Nosso Mundo: a Agenda 2030 para o Desenvolvimento Sustentável", que propõe 17 Objetivos do Desenvolvimento Sustentável e 169 Metas correspondentes, e a Constituição de 1988 do Brasil.

No primeiro item será trabalhado a erradicação da pobreza de forma geral e no segundo a erradicação da pobreza como objetivo fundamental constitucional do Brasil. Com isso pretende-se justamente responder se há diálogo entre Agenda 30 e a Constituição Federal em relação a erradicação da pobreza e se essa constitui-se como um elemento fundamental constitucional. 


\section{A ERRADICAÇÃO DA POBREZA E A AGENDA 2030 PARA O DESENVOLVIMENTO SUSTENTÁVEL}

Não há como ignorar a realidade da pobreza no mundo e no Brasil. A pobreza é um fato concreto que atinge a população mundial e a brasileira. Segundo publicado em outubro de $2017^{1}$, pode-se compreender o tamanho da pobreza no mundo pelos seguintes dados, in verbis:

- Uma em cada dez pessoas, ou 767 milhões no mundo todo, sobrevive com menos de US\$ 1,90 por dia, segundo a mais recente estimativa do Banco Mundial sobre pobreza e crescimento econômico;

- A pobreza entre trabalhadores é mais comum entre jovens de 15 a 24 anos. Cerca de $16 \%$ de trabalhadores nesta faixa etária vivem abaixo da linha da pobreza, ganhando menos de US\$ 1,90 por dia, enquanto $9 \%$ dos adultos estão na mesma situação;

- A região da África Subsaariana concentra mais pessoas em situação de pobreza extrema do que todo o resto do mundo. São cerca de 388 milhões, o que corresponde a mais de $40 \%$ da população local;

- A maior parte dos pobres no mundo vive em áreas rurais (80\%), tem menos de 14 anos (44\%), não tem educação formal (39\%) e é empregada na agricultura (65\%), aponta o relatório;

- Cerca de 1,1 bilhão de pessoas saíram da pobreza desde 1990, quando uma em cada três pessoas vivia nessa situação;

- Nas últimas três décadas, a diminuição da pobreza extrema ocorreu de forma mais rápida nas regiões do Sul Asiático, no Leste Asiático e no Pacífico. China, Indonésia e Índia se destacam na diminuição deste problema, segundo o Banco Mundial;

-. Apesar de ter apresentado melhora nos índices, a região do Sul Asiático tem o segundo maior número de pessoas na miséria. São 256 milhões de pessoas na pobreza extrema, ou $15 \%$ da população local; e,

- Em países pobres, uma a cada cinco pessoas recebe algum tipo de assistência ou benefício de proteção social. Já em nações de renda média e alta, duas a cada três recebem esse tipo de auxílio, segundo o último relatório da ONU sobre o cumprimento dos ODS.

Ainda na mesma publicação, quanto ao nosso país, esclareceu-se que:

- No Brasil, a desigualdade social piorou. Segundo o último relatório da ONU sobre o tema, o País caiu 19 posições na classificação que corresponde à diferença de renda entre ricos e pobres, na comparação entre 2014 e 2015 . Foi a primeira vez que o indicador social do IDH brasileiro piorou desde 1990, quando o levantamento começou a ser publicado anualmente;

- Entre 2014 e 2015 a proporção de pessoas vivendo na pobreza extrema no Brasil cresceu de 2,8\% para $3,4 \%$, e já atinge 6,8 milhões de pessoas, segundo dados da Pesquisa Nacional de Amostra por Domicílio (Pnad). O Banco Mundial estima que o número de miseráveis no País pode aumentar para 4,2\% até o fim de 2017, e atingir um total de 8,5 milhões de indivíduos; e,

- Até o final de 2017, o Brasil pode ter um aumento de 2,5 milhões a 3,6 milhões de pessoas que passarão a viver abaixo da linha da pobreza, segundo estimativa do Banco Mundial. Na hipótese mais otimista, segundo o estudo, a pobreza moderada atingiria $9,8 \%$ da população, ou 19,8 milhões de pessoas. A linha de pobreza moderada utilizada para os cálculos foi estipulada como 140 reais per capita por mês. Para a pobreza extrema, a média é de $\mathrm{R} \$ 70$ por pessoa em um mês.

Ipso facto, a fim de conformar o Capitalismo às exigências da atualidade em favor da liberdade do Homem, de todos os Homens, é necessário se edificar uma mentalidade jus-humanista de regência jurídica da economia e do mercado que, sem abominar este último e, pelo contrário,

\footnotetext{
${ }^{1}$ JORNAL O ESTADO DE S PAULO. Disponível em: https://sustentabilidade.estadao.com.br/noticias/geral,11estatisticas-que-mostram-o-tamanho-da-pobreza-no-mundo,70002027034. Acesso em 02 mar. 2018.
} 
recomendando-o, proponha-se a estruturar um Planeta Humanista de Direito que enfrente o problema da pobreza.

Daí, não obstante o caráter individualista das poderosas forças do mercado, se contemplará a efetivação multidimensional dos Direitos Humanos com vistas à satisfação universal da dignidade da pessoa humana e do Planeta, tendo por plataforma a ideia de um futuro comum.

Na órbita econômica, abrangendo o Capitalismo mundial, o Concílio Ecumênico Vaticano II, convocado no dia 25 de Dezembro de 1961, através da bula papal Humanae salutis, por João XXIII, exaltou as conhecidas lições de Tomás de Aquino, de que "Deus destinou a Terra com tudo o que ela contém para uso de todos os Homens e povos; de modo que os bens criados devem chegar equitativamente às mãos de todos, segundo a justiça secundada pela caridade. Sejam quais forem as formas de propriedade, conforme às legítimas instituições dos povos e segundo as diferentes e mutáveis circunstâncias, deve-se sempre atender a este destino universal dos bens. Por essa razão, quem usa desses bens, não deve considerar as coisas exteriores que legitimamente possui só como próprias, mas também como comuns, no sentido de que possam beneficiar não só a si mas também aos outros". 2

É a partir dos anos 80, através do célebre documento "Our Common Future", também conhecido como Relatório Brundtland, que uma Comissão constituída pela ONU resolve enfrentar o tema e o problema do desenvolvimento a partir de dúplice enfoque: o da sustentabilidade e o do meio ambiente. ${ }^{3}$

Tal desenvolvimento será aquele que "atende às necessidades do presente sem comprometer a possibilidade de as gerações futuras atenderem as suas próprias necessidades". ${ }^{4}$

Sob esta perspectiva foi proclamada a Declaração do Milênio das Nações Unidas de 2000, pela qual o mínimo concreto para a Humanidade seria a consecução dos oito Objetivos Gerais do Milênio (ODM): (1) erradicar a extrema pobreza e a fome; (2) atingir o ensino básico universal; (3) promover a igualdade de gênero e a autonomia das mulheres; (4) reduzir a mortalidade infantil; (5) melhorar a saúde materna; (6) combater o HIV/AIDS, a malária e outras doenças graves; (7) garantir a sustentabilidade ambiental; e (8) estabelecer uma parceria mundial para o desenvolvimento.

Passado o prazo dos quinze anos no que tange à verificação dos resultados das Metas do Milênio, a ONU, através do Relatório dos Objetivos de Desenvolvimento do Milênio 2015, revelou que os esforços para alcançar os oito Objetivos estabelecidos na Declaração do Milênio, em 2000, foram bem-sucedidos em todo o mundo, embora existam deficiências.

Quanto ao aludido Relatório, o então Secretário-Geral da ONU Ban Ki-moon declarou que "após ganhos profundos e consistentes, agora sabemos que a extrema pobreza pode ser erradicada dentro de uma geração"; e, ainda, que "os objetivos de desenvolvimento do milênio têm contribuído grandemente para esse progresso e nos ensinaram como os governos, empresas e sociedade civil podem trabalhar juntos para conseguir avanços transformacionais". 5

Em decorrência, as Nações Unidas deliberaram dar um passo adiante para proclamar os novos Objetivos de Desenvolvimento Sustentável (ODS), em torno de uma Agenda de Desenvolvimento, que é conhecida como Agenda 2030, a qual foi oficialmente adotada pelos

\footnotetext{
${ }^{2}$ VATICANO. CONSTITUIÇÃO PASTORAL GAUDIUM ET SPES, sobre a Igreja no Mundo de Hoje, ponto 69. Disponível em: http://www.vatican.va/archive/hist_councils/ii_vatican_council/documents/vat-

ii_const_19651207_gaudium-et-spes_po.html. Acesso em 20 fev.2018.

3 ORGANIZAÇÃO DAS NAÇÕES UNIDAS. Disponível em: http://www.onu.org.br/rio20/img/2012/01/N8718467.pdf. Acesso em: 25 fev.2018.

4 ORGANIZAÇÃO DAS NAÇÕES UNIDAS. Disponível em: http://www.onu.org.br/rio20/img/2012/01/N8718467.pdf. Acesso em: 25 fev.2018.

${ }^{5}$ NAÇÕES UNIDAS. Novo relatório da ONU avalia implementação mundial dos Objetivos de Desenvolvimento do Milênio (ODM). Disponível em: https://nacoesunidas.org/novo-relatorio-da-onu-avalia-implementacao-mundial-dosobjetivos-de-desenvolvimento-do-milenio-odm/. Acesso em: 02 mar. 2018.
}

Revista de Direito Brasileira | Florianópolis, SC | v. 22 | n. 9 | p.66-76 |Jan./Abr. 2019 
Chefes de Estado e de Governo do mundo todo, dentre eles o do Brasil, na Cúpula das Nações Unidas para o Desenvolvimento Sustentável de 2015.

As principais diferenças entre os ODM e os ODS, está na amplitude dos temas abordados e na abrangência da aplicação, conforme Silveira e Pereira. Os autores explicam:

Isso porque os ODS tratam de um maior número de questões e com maior profundidade em relação aos ODM, como, por exemplo, da segurança alimentar, sustentabilidade na agricultura, disponibilidade e gestão da água e saneamento, acesso à energia, emprego pleno e produtivo, construção de infraestrutura e promoção da industrialização, segurança e sustentabilidade de cidades e assentamentos humanos, consumo sustentável, mudanças climáticas, conservação dos oceanos, gestão das florestas e combate à desertifiação e acesso à justiça e instituições eficazes. Com relação à aplicabilidade, enquanto os ODM estavam focados nos países pobres, os ODS possuem uma ação mais ampla com perspectiva de alcance global, portanto são universalmente aplicáveis. Contudo, é importante observar que a Agenda 2030 em que estão inseridos os ODS não foi formalizada como tratado, desse modo não possui efeito vinculante, 41 haja vista ser norma de soft law. ${ }^{6}$

Concluídas em agosto de 2015, as negociações multilaterais da Agenda 2030, foi formalizada e oficialmente adotada a ambiciosa Resolução "Transformando Nosso Mundo: a Agenda 2030 para o Desenvolvimento Sustentável"7, que propõe 17 Objetivos do Desenvolvimento Sustentável e 169 Metas correspondentes, mercê do consenso entre os delegados dos Estados-membros da ONU, dentre os quais está o Brasil, assinalando que a respectiva implementação ocorrerá no período entre 2016/2030.

Como declara a referida Resolução:

Os objetivos e metas são o resultado de mais de dois anos de consulta pública intensiva e envolvimento junto à sociedade civil e outras partes interessadas em todo o mundo, prestando uma atenção especial às vozes dos mais pobres e mais vulneráveis. Esta consulta incluiu o valioso trabalho realizado pelo Grupo de Trabalho Aberto sobre Objetivos de Desenvolvimento Sustentável da Assembleia Geral e pelas Nações Unidas.

Em nome dos povos que servem, aqueles Chefes de Estado e de Governo e altos representantes adotaram "uma decisão histórica sobre um conjunto de Objetivos e metas universais e transformadoras que é abrangente, de longo alcance e centrado nas pessoas".

Comprometeram-se "a trabalhar incansavelmente para a plena implementação desta Agenda em 2030". Reconheceram "que a erradicação da pobreza em todas as suas formas e dimensões, incluindo a pobreza extrema, é o maior desafio global e um requisito indispensável para o desenvolvimento sustentável". Declararam-se "empenhados em alcançar o desenvolvimento sustentável nas suas três gerações - econômica, social e ambiental - de forma equilibrada e integrada". Assumiram, também, que seus Estados vão "dar continuidade às conquistas dos Objetivos de Desenvolvimento do Milênio e buscar atingir suas metas inacabadas".

Eles resolveram, que entre 2016 e 2030 , pretendem "acabar com a pobreza e a fome em todos os lugares; combater as desigualdades dentro e entre os países; construir sociedades pacíficas, justas e inclusivas; proteger os Direitos Humanos e promover a igualdade de gênero e o empoderamento das mulheres e meninas; e assegurar a proteção duradoura do Planeta e seus recursos naturais". Resolveram, também, "criar condições para um crescimento sustentável,

\footnotetext{
${ }^{6}$ SILVEIRA, V.O.; PEREIRA, T.M.L. Uma nova compreensão dos Direitos Humanos na Contemporaneidade a partir dos Objetivos de Desenvolvimento Sustentável (ODS). In: Revista Jurídica Unicesumar, São Paulo, v.18, n.3, p.921, set./dez. 2018.

${ }^{7}$ NAÇÕES UNIDAS. Agenda 30. Disponível em: https://nacoesunidas.org/pos2015/agenda2030/. Acesso em: 02 mar. 2018.
} 
inclusivo e economicamente sustentado, prosperidade compartilhada e trabalho digno para todos, tendo em conta os diferentes níveis de desenvolvimento e capacidades nacionais".

Declararam estes os Chefes de Estado e de Governo e altos representantes que embarcaram "nesta grande jornada coletiva"; e, comprometeram-se "que ninguém será deixado para trás". Reconheceram "a dignidade da pessoa humana como fundamental"; e, querem "ver os Objetivos e metas cumpridos para todas as nações e povos e para todos os segmentos da sociedade". Eles afirmaram que será feito "o possível para alcançar, em primeiro lugar, aqueles que ficaram mais para trás".

Proclamaram que "esta é uma Agenda de alcance e significado sem precedentes. Ela é aceita por todos os países e é aplicável a todos, levando em conta diferentes realidades nacionais, capacidades e níveis de desenvolvimento e respeitando as políticas e prioridades nacionais.

Estes são objetivos e metas universais que envolvem todo o mundo, igualmente os países desenvolvidos e os em desenvolvimento. Eles são integrados e indivisíveis, e equilibram as dimensões do desenvolvimento sustentável.

Pelos olhos destes Chefes de Estado e de Governo e altos representantes foi materializado que nestes Objetivos e metas, se está "estabelecendo uma visão extremamente ambiciosa e transformadora", para se prever "um mundo livre da pobreza, fome, doença e penúria, onde toda a vida pode prosperar".

$\mathrm{Na}$ declaração, se prevê, ainda, "um mundo livre do medo e da violência. Um mundo com alfabetização universal. Um mundo com o acesso equitativo e universal à educação de qualidade em todos os níveis, aos cuidados de saúde e proteção social, onde o bem-estar físico, mental e social estão assegurados".

Um mundo em que aqueles Chefes de Estado e de Governo e altos representantes reafirmam os "compromissos relativos ao direito humano à água potável e ao saneamento e onde há uma melhor higiene; e onde o alimento é suficiente, seguro, acessível e nutritivo. Um mundo onde habitats humanos são seguros, resilientes e sustentáveis, e onde existe acesso universal à energia acessível, confiável e sustentável”.

A Declaração da Agenda 2030, formalizada pelos líderes Mundiais ou seus altos representantes, expressamente faz a previsão de "um mundo de respeito universal dos Direitos Humanos e da dignidade humana, do Estado de Direito, da justiça, da igualdade e da não discriminação; do respeito pela raça, etnia e diversidade cultural; e da igualdade de oportunidades que permita a plena realização do potencial humano e contribua para a prosperidade compartilhada. Um mundo que investe em suas crianças em que cada criança cresça livre da violência e da exploração. Um mundo em que cada mulher e menina desfruta da plena igualdade de gênero e no qual todos os entraves jurídicos, sociais e econômicos para seu empoderamento foram removidos. Um mundo justo, equitativo, tolerante, aberto e socialmente inclusivo em que sejam atendidas as necessidades das pessoas mais vulneráveis".

Nesse sentido, Silveira e Pereira afirmam que "os Objetivos de Desenvolvimento Sustentável são reflexos do atual estágio dos direitos humanos globalmente considerados, seja porque consistem numa reafirmação do rol de tais direitos, seja porque trazem metas concretas com a finalidade de alcançá-los e protegê-los."

Os autores vão além, assegurando que:

alguns objetivos e metas consistem verdadeiramente em reiterações de direitos civis e políticos e direitos econômicos, sociais e culturais já consagrados (direitos de primeira e segunda geração). Outros, dizem respeito às formas de implementação de tais direitos, notadamente os sociais, dispondo sobre meios

\footnotetext{
${ }^{8}$ SILVEIRA, V.O.; PEREIRA, T.M.L. Uma nova compreensão dos Direitos Humanos na Contemporaneidade a partir dos Objetivos de Desenvolvimento Sustentável (ODS). In: Revista Jurídica Unicesumar, São Paulo, v.18, n.3, p.924, set./dez. 2018.
}

Revista de Direito Brasileira | Florianópolis, SC | v. 22 | n. 9 | p.66-76 |Jan./Abr. 2019 
concretos para se alcançar o desenvolvimento sustentável, inclusive no que toca a questões financeiras, de disponibilização de crédito e de crescimento econômico dos países, consistindo assim em preceitos relativos aos direitos de terceira geração. ${ }^{9}$

A Agenda 30 ainda prevê, "um mundo em que cada país desfrute de um crescimento econômico sustentado, inclusivo e sustentável e de trabalho digno para todos. Um mundo em que os padrões de consumo e produção e o uso de todos os recursos naturais - do ar à terra; dos rios, lagos e aquíferos aos oceanos e mares - são sustentáveis. Um mundo em que a democracia, a boa governança e o Estado de Direito, bem como um ambiente propício em níveis nacional e internacional, são essenciais para o desenvolvimento sustentável, incluindo crescimento econômico inclusivo e sustentado, desenvolvimento social, proteção ambiental e erradicação da pobreza e da fome. Um mundo em que o desenvolvimento e a aplicação da tecnologia são sensíveis ao clima, respeitem a biodiversidade e são resilientes. Um mundo em que a Humanidade viva em harmonia com a natureza e em que animais selvagens e outras espécies vivas estão protegidos."

Parece um sonho, uma utopia, mas não é; pois corresponde a um sério compromisso firmado pelos Chefes de Estado e de Governo e altos representantes dos países do mundo todo, dentre os quais está incluído o Brasil, que, perante à ONU, não estavam a brincar.

Aqueles Chefes de Estado e de Governo e altos representantes dos países do mundo todo, dentre os quais está incluído o Brasil, estavam absolutamente cientes da realidade mundial naquele momento; tanto que, consignaram na Declaração da Agenda 2030, que a Humanidade se encontra "num momento de enormes desafios para o desenvolvimento sustentável. Bilhões de cidadãos continuam a viver na pobreza e a eles é negada uma vida digna. Há crescentes desigualdades dentro dos e entre os países. Há enormes disparidades de oportunidades, riqueza e poder. A desigualdade de gênero continua a ser um desafio fundamental. O desemprego, particularmente entre os jovens, é uma grande preocupação. Ameaças globais de saúde, desastres naturais mais frequentes e intensos, conflitos em ascensão, o extremismo violento, o terrorismo e as crises humanitárias relacionadas e o deslocamento forçado de pessoas ameaçam reverter grande parte do progresso do desenvolvimento feito nas últimas décadas".

Para tanto e em primeiro lugar, a Declaração da Agenda 2030 estabeleceu, dentro outros 17 Objetivos de Desenvolvimento Sustentável, o Objetivo de "Acabar com a pobreza em todas as suas formas, em todos os lugares", fixando as metas, a saber:

1.1 - Até 2030, erradicar a pobreza extrema para todas as pessoas em todos os lugares, atualmente medida como pessoas vivendo com menos de US\$ 1,25 por dia;

1.2 - Até 2030, reduzir pelo menos à metade a proporção de Homens, mulheres e crianças, de todas as idades, que vivem na pobreza, em todas as suas dimensões, de acordo com as definições nacionais;

1.3 - Implementar, em nível nacional, medidas e sistemas de proteção social adequados, para todos, incluindo pisos, e até 2030 atingir a cobertura substancial dos pobres e vulneráveis;

1.4 - Até 2030, garantir que todos os Homens e mulheres, particularmente os pobres e vulneráveis, tenham direitos iguais aos recursos econômicos, bem como o acesso a serviços básicos, propriedade e controle sobre a terra e outras formas de propriedade, herança, recursos naturais, novas tecnologias apropriadas e serviços financeiros, incluindo microfinanças;

\footnotetext{
${ }^{9}$ SILVEIRA, V.O.; PEREIRA, T.M.L. Uma nova compreensão dos Direitos Humanos na Contemporaneidade a partir dos Objetivos de Desenvolvimento Sustentável (ODS). In: Revista Jurídica Unicesumar, São Paulo, v.18, n.3, p.924, set./dez. 2018.
}

Revista de Direito Brasileira | Florianópolis, SC | v. 22 | n. 9 | p. 66-76 |Jan./Abr. 2019 
1.5 - Até 2030, construir a resiliência dos pobres e daqueles em situação de vulnerabilidade, e reduzir a exposição e vulnerabilidade destes a eventos extremos relacionados com o clima e outros choques e desastres econômicos, sociais e ambientais;

1.a - Garantir uma mobilização significativa de recursos a partir de uma variedade de fontes, inclusive por meio do reforço da cooperação para o desenvolvimento, para proporcionar meios adequados e previsíveis para que os países em desenvolvimento, em particular os países menos desenvolvidos, implementem programas e políticas para acabar com a pobreza em todas as suas dimensões; e,

1.b - Criar marcos políticos sólidos em níveis nacional, regional e internacional, com base em estratégias de desenvolvimento a favor dos pobres e sensíveis a gênero, para apoiar investimentos acelerados nas ações de erradicação da pobreza.

Perceba-se que, um dos princípios da Agenda 2030, expressamente consagrado pela ONU, na respectiva Declaração, é a prosperidade, tendo em vista que, como está declarado, os Chefes de Estado e Governo e altos representantes dos países do mundo estão "determinados a assegurar que todos os seres humanos possam desfrutar de uma vida próspera e de plena realização pessoal, e que o progresso econômico, social e tecnológico ocorra em harmonia com a natureza".

\section{A ERRADICAÇÃO DA POBREZA COMO OBJETIVO FUNDAMENTAL CONSTITUCIONAL}

Com este atual modo de ver, embasado no item anterior, está declarado pelos Chefes de Estado e Governo e altos representantes dos países do mundo que o preconceito contra os Direitos Humanos que dominava a questão do desenvolvimento se vê vencido pela visão humanista que há de erradicar a pobreza, ou seja, abolir a privação das pessoas a níveis dignos de subsistência.

Entretanto, esses Direitos Humanos não podem ser reduzidos à esfera de interesse da soberania de cada Estado, pois estão ligados ao próprio destino da humanidade. ${ }^{10}$ Isto, no entendimento de Silveira e Contipelli, tem implicação no compartilhamento de parcela da ordem jurídica interna, que passa a admitir intervenções e responsabilizações no plano externo, em razão da titularidade destes valores que compreende o indivíduo como sujeito de direitos, carente de proteção internacional. Tal entendimento teórico encontra relevância prática, uma vez que os Estados, com todos os avanços e amarras do constitucionalismo moderno, já foram historicamente os maiores violadores dos direitos humanos, e oportunamente são vistos como grandes garantidores dos direitos humanos (fundamentais). ${ }^{11}$

Assim a Constituição Federal brasileira, proclamada há 30 anos, em 1988, já estabelecia em seu art. 3, III, que a erradicação da pobreza era um dos objetivos fundamentais da República, ex vi de seus próprios termos, "Art. 3. Constituem objetivos fundamentais da República Federativa do Brasil: III- erradicar a pobreza e a marginalização a reduzir as desigualdades sociais e regionais."

Verifica-se, portanto, que com a preocupação de erradicação da pobreza, o Constituinte brasileiro de 1988, estava na vanguarda da humanidade, tendo-se antecipado à ONU quanto às Metas do Milênio de 2000; e, a Agenda 2030, adotada em 2015.

Assim sendo, estes 30 anos que se passaram da promulgação da atual Constituição Federal, demonstraram que os Constituintes brasileiros estavam no caminho correto dos anseios da

${ }^{10}$ SILVEIRA, V.O.; CONTIPELLI, E. Direitos Humanos Econômicos na perspectiva da Solidariedade: Desenvolvimento Integral. In: XVI Encontro Nacional CONPEDI, 2008, Salvador - BA. Anais XVI Encontro Nacional do CONPEDI, 2008, p.2578.

${ }^{11}$ SILVEIRA, V.O.; CONTIPELLI, E. Direitos Humanos Econômicos na perspectiva da Solidariedade: Desenvolvimento Integral. In: XVI Encontro Nacional CONPEDI, 2008, Salvador - BA. Anais XVI Encontro Nacional do CONPEDI, 2008, p.2578. 
humanidade, ao pronunciarem expressamente que, como representantes do povo, reunidos em Assembleia Nacional para instituir um Estado Democrático, buscaram assegurar os exercícios dos direitos sociais individuais, a liberdade, a segurança, o bem estar, o desenvolvimento, a igualdade e a justiça como valores supremos de uma sociedade fraterna.

A fraternidade na Constituição Federal de 1988, deixou de ser uma inspiração filosófica ou até teológica, para se convolar em uma categoria jurídica, residente no ápice do sistema normativo, diante de sua natureza constitucional.

Erradicar a pobreza significará que todos estrarão igualados no que tange aos níveis dignos de subsistência, via de consequência, a partir desta igualdade na base de uma vida digna, todos terão a real liberdade de promover suas potencialidades ao infinito. Com a erradicação da pobreza, a meta constitucional é que não haja limite para a prosperidade, contudo seja abolida a miséria, sendo que cada um é especialmente responsável por seu posicionamento entre tais níveis dignos de subsistência e a sua própria e pessoal condição. Erradicada a pobreza, o Homem e todos os Homens passam a ser senhores de seus próprios passos, todavia, imunes à miséria econômica.

Ressaltando-se que, o acesso a níveis dignos de subsistência também é categoria constitucional brasileira, na medida em que se encontra reconhecido literalmente no art. 79, do Ato das Disposições Constitucionais Transitórias.

Ademais, em desdobramento do objetivo fundamental de erradicação da pobreza, o art. 170, caput, da Constituição Federal, proclama, para a ordem econômica, o fim, que equivale a objetivo, de garantir a todos existência digna.

Ora o que seria existência digna sob o ponto de vista da ordem econômica, senão estar imune à pobreza, ou seja, ter acesso a níveis dignos de subsistência. Não é redundância afirmar, até porque são categorias constitucionais distintas e reconhecidas em passagens diferentes do texto magno, que existência digna, sob o ponto de vista da ordem econômica, é aquela em que a pessoa humana tem acesso a níveis dignos de subsistência.

Então, para não haver deselegância, sem mencionar fontes, é ultrapassada e inaceitável a visão daquele constitucionalismo que despreza a categoria constitucional dos objetivos fundamentais da república, atribuindo-lhes pouca relevância jurídica. Pior ainda é aquela visão constitucional que entende o objetivo fundamental constitucional de erradicação da pobreza como uma preposição sem eficácia e meramente retórica e romântica do Constituinte.

Pelo contrário, como a ONU demonstrou em seus aludidos pronunciamentos, não há nada mais moderno e relevante do que o objetivo de desenvolvimento sustentável de erradicação da pobreza.

\section{CONCLUSÃO}

Como observado na pesquisa, a erradicação efetiva da pobreza será a expressão do Brasil que todos queremos. A expressão de um Novo Brasil, totalmente rompido com a ordem anterior de tolerância com a pobreza, por ser um fato da vida. A nova ordem diz não à pobreza e a elenca como o alvo a ser combatido. Chama atenção, o fato histórico de que a fixação da preocupação da meta da erradicação da pobreza como objetivo fundamental da República, ocorreu em um contexto de emersão de poder constituinte originário. Com efeito, há um entendimento pacificado na melhor doutrina nacional, que a Constituição de 1988 é norma constitucional originaria, não obstante, decorrente de convocação por meio da Emenda Constitucional n 26, de 1985.

Embora tenha sido por esta modalidade pacífica de convocação, a Assembleia Nacional Constituinte, livre e soberana, instalada a partir do dia 01/02/87, representou realmente uma ruptura no sistema constitucional anterior, edificando no país uma nova ordem jurídica constitucional, absolutamente distinta da antecessora, contudo sem a separação por meio do vermelho do sangue de uma revolução violenta que felizmente não ocorreu. 
A ausência de violência não significou a inocorrência de uma revolução institucional a ponto de romper com a ordem jurídica anterior. É que, dentre os traços marcantes da nova ordem constitucional, rompendo o Estado de Direito que já havia no sistema anterior, o Constituinte de 88 consagrou uma nova ordem constitucional baseada no genuíno ideal democrático e nos direitos humanos.

Pela primeira vez na história nacional, não obstante as diversas constituições anteriores, a nossa Carta Magna de 88 consagra o Brasil como Estado Democrático de Direito, assim como, a dignidade da pessoa humana como princípio fundamental da república.

Ainda pela primeira vez, na nossa história das Constituições Federais, o Constituinte se refere por sete vezes no texto constitucional à categoria jurídica dos direitos humanos.

$\mathrm{Na}$ crescente valorização da categoria dos direitos humanos como matriz jurídica da estruturação da nova ordem constitucional de 1988, e ruptura da anterior, basta constatar o incremento promovido pela Emenda Constitucional $n^{\circ} 45$, de 2004 , que inseriu o parágrafo terceiro no art. $5^{\circ}$, para dispor que os tratados e convenções internacionais sobre direitos humanos que forem aprovados, em cada casa do Congresso Nacional, em dois turnos, por três quintos dos votos dos respectivos membros, serão equivalentes às emendas constitucionais.

O prestígio dos direitos humanos e, especialmente, sua expressão objetiva, a dignidade da pessoa humana, está reconhecido pela iterativa jurisprudência do Supremo Tribunal Federal e dos demais tribunais do Poder Judiciário brasileiro.

Logo, à luz da Constituição Federal do Brasil, de 1988, em conformidade com os direitos humanos e a dignidade da pessoa humana, sob o ponto de vista da respectiva dimensão econômica, que batizamos de Capitalismo Humanista, é manifestamente relevante se reconhecer que, na construção da sociedade fraterna que venha a sustentar nosso Estado Democrático de Direito, a conquista integral da liberdade do Homem e de todos os Homens, pressupõe que a pobreza seja o alvo constitucional a ser erradicado.

A Constituição Federal, agora aos seus trinta anos, hoje mais do que antes, proclama, pois, que para o Brasil, embora seja capitalista, a pobreza é o inimigo comum da liberdade, determinando a restauração da igualdade jamais conquistada, mercê da quebra de simetria entre todos, que a muitos exclui para a miséria econômica, não obstante seja garantido aos brasileiros e estrangeiros residentes no país, o acesso universal a níveis dignos de subsistência.

\section{REFERÊNCIAS}

JORNAL O ESTADO DE S PAULO. Disponível em:

https://sustentabilidade.estadao.com.br/noticias/geral,11-estatisticas-que-mostram-o-tamanho-dapobreza-no-mundo,70002027034. Acesso em 02 mar. 2018.

NAÇÕES UNIDAS NO BRASIL. Novo relatório da ONU avalia implementação mundial dos Objetivos de Desenvolvimento do Milênio (ODM). Disponível em: https://nacoesunidas.org/novo-relatorio-da-onu-avalia-implementacao-mundial-dos-objetivos-dedesenvolvimento-do-milenio-odm/. Acesso em: 02 mar. 2018.

NAÇÕES UNIDAS NO BRASIL. Agenda 2030. Disponível em: https://nacoesunidas.org/pos2015/agenda2030/. Acesso em: 02 mar. 2018.

ORGANIZAÇÃO DAS NAÇÕES UNIDAS. Disponível em: http://www.onu.org.br/rio20/img/2012/01/N8718467.pdf. Acesso em: 20 fev. 2018. 
SILVEIRA, V.O.; PEREIRA, T.M.L. Uma nova compreensão Dos Direitos Humanos Na Contemporaneidade A Partir Dos Objetivos De Desenvolvimento Sustentável (ODS). In: Revista Jurídica Unicesumar, São Paulo, v.18, n.3, pp.909-931, set./dez. 2018.

SILVEIRA, V.O.; CONTIPELLI, E. Direitos Humanos Econômicos na perspectiva da Solidariedade: Desenvolvimento Integral. In: XVI Encontro Nacional CONPEDI, 2008, Salvador - BA. Anais XVI Encontro Nacional do CONPEDI, 2008.

VATICANO. Constituição Pastoral Gaudium et Spes, sobre a Igreja no Mundo de Hoje, ponto 69. Disponível em:

http://www.vatican.va/archive/hist_councils/ii_vatican_council/documents/vatii_const_19651207_gaudium-et-spes_po.html. Acesso em 20 fev. 2018. 